\begin{tabular}{|c|c|}
\hline Title & Ribavirin-related compounds exert in vitro inhibitory effects toward rabies virus. \\
\hline Author(s) & $\begin{array}{l}\text { A nindita, Paulina D; Sasaki, Michihito; Okada, Kazuma; Ito, Naoto; Sugiyama, Makoto; Saito-Tarashima, Noriko; } \\
\text { Minakawa, Noriaki; Shuto, Satoshi; Otsuguro, Satoko; Ichikawa, Satoshi; Matsuda, A kira; Maenaka, Katsumi; Orba, } \\
\text { Y asuko; Sawa, Hirofumi }\end{array}$ \\
\hline Citation & $\begin{array}{l}\text { A ntiviral research, 154, 1-9 } \\
\text { https://doi.org/10.1016/.antiviral .2018.03.011 }\end{array}$ \\
\hline Issue Date & $2018-06$ \\
\hline Doc URL & http:/hdl.handle.net/2115/74611 \\
\hline Rights & $\begin{array}{l}\text { (2018. This manuscript version is made available under the CC-BY-NC-ND } 4.0 \text { license } \\
\text { http://creativecommons.org/icenses/by-nc-nd/4.0/ }\end{array}$ \\
\hline Rights(URL) & https://creativecommons.org/icenses/by-nc-nd/4.0/ \\
\hline Type & article (author version) \\
\hline File Information & JID(files integrated).pdf \\
\hline
\end{tabular}

Instructions for use 


\section{Ribavirin-Related Compounds Exert In Vitro Inhibitory Effects toward Rabies Virus}

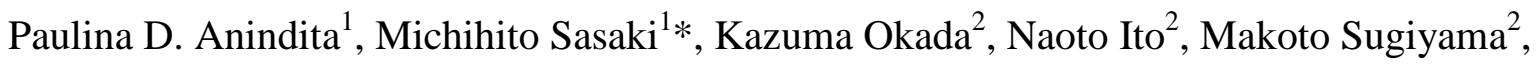
Noriko Saito-Tarashima $^{3}$, Noriaki Minakawa ${ }^{3}$, Satoshi Shuto ${ }^{4}$, Satoko Otsuguro ${ }^{5}$, Satoshi Ichikawa $^{5}$, Akira Matsuda ${ }^{5}$, Katsumi Maenaka ${ }^{5}$, Yasuko Orba ${ }^{1}$, and Hirofumi Sawa ${ }^{1,6,7 *}$

${ }^{1}$ Division of Molecular Pathobiology, Research Center for Zoonosis Control, Hokkaido University, Sapporo 001-0020, Japan

${ }^{2}$ Laboratory of Zoonotic Diseases, Faculty of Applied Biological Sciences, Gifu University, Gifu 501-1193, Japan

${ }^{3}$ Graduate School of Pharmaceutical Science, Tokushima University, Tokushima 770-8505, Japan

${ }^{4}$ Laboratory of Organic Chemistry for Drug Development, Faculty of Pharmaceutical Sciences, Hokkaido University, Sapporo 060-0812, Japan

${ }^{5}$ Center for Research and Education on Drug Discovery, Faculty of Pharmaceutical Sciences, Hokkaido University, Sapporo 060-0812, Japan

${ }^{6}$ Global Institution for Collaborative Research and Education (GI-CoRE), Hokkaido University, Sapporo 001-0020, Japan

${ }^{7}$ Global Virus Network, Baltimore, Maryland 21201, United States of America

\section{Conflict of interest statement}

All authors declare that they have no conflict of interest.

RABV, rabies virus; GTP; guanosine triphosphate; IMPDH, inosine monophosphate dehydrogenase enzyme; CNS, central nervous system; rRABV, recombinant RABV; Nluc, NanoLuc luciferase; BHK, baby hamster kidney; HEK, human embryonic kidney; MEM, minimum essential medium; FBS, fetal bovine serum; CVS, challenge virus standard; EICAR, 5-ethynyl-1- $\beta$-D-ribofuranosylimidazole-4carboxamide; EICNR, 5-ethynyl-1- $\beta$-D-ribofuranosylimidazole-4-carbonitrile; BICAR, 5-5-buthynyl-1- $\beta$-D-ribofuranosylimidazole-4carboxamide; mizoribine, 4-carbamoyl-1- $\beta$-D-ribofuranosylimidazolium-5-olate; MOI, multiplicity of infection, FFU, focus forming unit; hpi, hours post-infection; DMSO, dimethyl sulfoxide; PBS, phosphate buffered saline; FITC, fluorescein isothiocyanate; MTT, 3-(4,5Dimethylthiazol-2-yl)-2,5-diphenyltetrazolium bromide; ORF, open reading frame; HA, hemagglutinin 
*Corresponding authors

Michihito Sasaki, Division of Molecular Pathobiology, Research Center for Zoonosis

Control, Hokkaido University, Sapporo 001-0020, Japan

Tel: +81 11706 9513; Fax: +81 11706 7370; E-mail address: m-sasaki@czc.hokudai.ac.jp

Hirofumi Sawa, Division of Molecular Pathobiology, Research Center for Zoonosis Control, Hokkaido University, Sapporo 001-0020, Japan

Tel: +81 11706 5185; Fax: +81 11706 7370; E-mail address: h-sawa@czc.hokudai.ac.jp

Running text: Anti-RABV activity of ribavirin analogs

Word counts for the abstract: 182

Word counts for the text: 3416 


\begin{abstract}
Rabies remains an invariably fatal neurological disease despite the availability of a preventive vaccination and post-exposure prophylaxis that must be immediately administered to the exposed individual before symptom onset. There is no effective medication for treatment during the symptomatic phase. Ribavirin, a guanine nucleoside analog, is a potent inhibitor of rabies virus (RABV) replication in vitro but lacks clinical efficacy. Therefore, we attempted to identify potential ribavirin analogs with comparable or superior anti-RABV activity. Antiviral activity and cytotoxicity of the compounds were initially examined in human neuroblastoma cells. Among the tested compounds, two exhibited a 5- to 27-fold higher anti-RABV activity than ribavirin. Examination of the anti-RABV mechanisms of action of the compounds using time-of-addition and minigenome assays revealed that they inhibited viral genome replication and transcription. Addition of exogenous guanosine to RABV-infected cells diminished the antiviral activity of the compounds, suggesting that they are involved in guanosine triphosphate (GTP) pool depletion by inhibiting inosine monophosphate dehydrogenase (IMPDH). Taken together, our findings underline the potency of nucleoside analogs as a class of antiviral compounds for the development of novel agents against RABV.
\end{abstract}

Keywords: rabies virus; antiviral; compound; nucleoside analog 


\section{Introduction}

Rabies is a vaccine-preventable infectious viral disease that damages the CNS of animals and humans. A post-exposure prophylaxis approved by World Health Organization involves the administration of rabies vaccine and immunoglobulin and is available to treat individuals exposed to RABV, but it must be administered before the clinical onset (Appolinario and Jackson, 2015; Rupprecht and Gibbons, 2004). Despite a few reported cases of individuals surviving symptomatic rabies, including one case that was treated with the Milwaukee Protocol (Jackson, 2013), it is extremely challenging to treat symptomatic patients. Once the virus reaches the CNS and neurological symptoms develop, the disease is invariably fatal. Known antiviral agents, such as amantadine and interferon alpha, failed to demonstrate therapeutic efficacy in a mouse model and clinical cases of RABV.

Only two nucleoside analogs have been sufficiently investigated for their anti-RABV effect. Ribavirin, a broad-spectrum guanine nucleoside analog, inhibited RABV replication in vitro but failed to demonstrate a protective efficacy in human clinical cases (Appolinario and Jackson, 2015; Bussereau et al., 1988; Warrell et al., 1989). Favipiravir (T-705), the other nucleoside analog, exhibited potency as a rabies post-exposure prophylaxis in a mouse model (Yamada et al., 2016), suggesting that nucleoside analogs could act as potential anti-RABV agents. Further study revealed that T-705 displayed limited use as a single treatment entity for rabies, and its use as a part of a multi-drug treatment remains unknown (Banyard et al., 2017). Therefore, more compounds need to be identified to further pursue the potency of nucleoside analogs in rabies treatment, especially during the symptomatic phase of the disease.

The structure of nucleoside analogs resembles endogenous cellular nucleosides, critically required for nucleic acid biosynthesis, and they act as competitive inhibitors during viral genome replication (Jordheim et al., 2013). The inhibitory mechanisms of action against 
viruses are thought to involve: (i) inhibition of inosine monophosphate dehydrogenase (IMPDH) function (Balzarini et al., 1993; Debing et al., 2014; Leyssen et al., 2005), (ii) interference of viral genome replication by direct incorporation into nascent viral genomes thus inducing lethal mutagenesis (Baranovich et al., 2013; Crotty et al., 2000; Shah et al., 2010; Sun et al., 2007), and (iii) inhibition of mRNA capping (Benarroch et al., 2004).

Anti-RABV agents can be identified by examining compound libraries using either cellbased (Bussereau et al., 1983; Chávez et al., 2006) or cell-free screening assays (Lingappa et al., 2013). Cell-based systems using native RABV infection of susceptible cell lines have provided a more robust and replicable approach to identify anti-RABV compounds (Bussereau et al., 1983; Bussereau and Ermine, 1983; Chávez et al., 2006). Therefore, we employed a cell-based system using previously generated rRABV encoding Nluc (Anindita et al., 2016). Several ribavirin analogs were tested. Their in vitro anti-RABV activity was compared to that of ribavirin to provide more detailed information with regards to the structure of chemical compounds provoking potent inhibitory effects on RABV replication.

\section{Materials and methods}

\subsection{Cells and viruses}

BHK clone 13 (BHK-21 [C-13]), human neuroblastoma (SK-N-SH), and mouse neuroblastoma (NA) cells were maintained in MEM supplemented with 10\% FBS. HEK 293T cells were maintained in high glucose Dulbecco’s modified MEM supplemented with $10 \%$ FBS.

Previously generated rRABV encoding Nluc, CVS-Nluc (N-P) (Anindita et al., 2016), and rRABV encoding a wild type CVS genome, CVS-WT, were employed in this study. Virus stocks of CVS-Nluc (N-P) and CVS-WT were prepared in NA cells. Virus titers were determined using a focus forming assay. 


\subsection{Compounds}

EICAR, EICNR, and BICAR were synthesized following previous study (Minakawa et al., 1991). Each compound was prepared and purified by crystallization or high-performance liquid chromatography (>95\%). Mizoribine was a generous gift from Asahi Chemical Industry Co., Ltd. (Tokyo, Japan). Ribavirin was purchased from Wako Pure Chemical Industries, Ltd., (Osaka, Japan). Guanosine, adenosine, cytidine, and uridine were purchased from Sigma-Aldrich (St. Louis, MO, USA).

\subsection{Infection experiments}

SK-N-SH, NA, BHK, and HEK 293T cells seeded into 96-well plates on the previous day were treated with two-fold serially diluted compounds starting from $20 \mu \mathrm{M}$. The cells were then infected with CVS-Nluc (N-P) at an MOI of 0.1 or 1 for SK-N-SH or NA, BHK-21 [C-13], and HEK 293T cells, respectively. The MOI was calculated as FFU/cell. Following incubation for $24 \mathrm{~h}$, luciferase assay was performed using the Nano-Glo® Luciferase Assay System (Promega Corporation, Madison, WI) and a GloMax® 96 Microplate Luminometer (Promega Corporation, Madison) to measure Nluc activity. The measured Nluc activity was expressed in relative luciferase unit (RLU)/sec.

The anti-RABV activity of the compounds was evaluated in the presence of exogenous nucleosides. Briefly, SK-N-SH cells seeded a day prior into 96-well plates were infected with CVS-Nluc (N-P) at an MOI of 0.1. Following $1 \mathrm{~h}$ incubation, the infected cells were treated with each compound in two-fold serial dilutions starting from $10 \mu \mathrm{M}$ together with $30 \mu \mathrm{M}$ nucleoside. The luciferase assay was performed at 24 hpi. Similar experiments were also performed to measure the anti-RABV activity of individual nucleosides. 


\subsection{Immunofluorescence assay}

SK-N-SH cells were seeded into 96-well plates a day prior. Following treatment with the compounds for $1 \mathrm{~h}$, the cells were inoculated with CVS-WT at an MOI of 5. After washing with PBS, they were incubated with fresh medium containing the compounds. At 16 hpi, the cells were fixed with 10\% formaldehyde and stained with FITC-conjugated antiRABV N antibody (Fujirebio Diagnostics, Inc., Malvern, PA, USA), and Hoechst 33342 (Molecular Probes, Eugene, OR, USA) was used to stain cell nuclei. The fluorescence signals were detected using an inverted fluorescence microscope, Olympus IX70 (Olympus, Tokyo, Japan).

\subsection{Focus forming assay}

NA cells seeded into 24-well plates were inoculated with virus stocks or culture supernatants from the infected cells diluted ten-fold. Following incubation for $1 \mathrm{~h}$ at $37^{\circ} \mathrm{C}$ on a plate shaker, an overlay medium containing MEM supplemented with 5\% FBS; penicillin (100 U/ml), streptomycin (100 mg/ml), and 0.5\% methylcellulose was added. Virus foci were detected using an FITC-conjugated anti-RABV N antibody (Fujirebio Diagnostics, Inc.) after 3 days of incubation. The number of foci was counted to determine the virus titer (FFU/ml).

\subsection{Cell viability assay}

Compound cytotoxicity was analyzed using the MTT assay following described procedure (Wada et al., 2017). Cell monolayers cells were seeded in 96-well plates a day before treatment with two-fold serial dilutions of the compounds for $24 \mathrm{~h}$ incubation. Thereafter, MTT assay was performed and the absorbance at a $570 \mathrm{~nm}$ with a $630 \mathrm{~nm}$ reference wavelength was measured using an iMark ${ }^{\mathrm{TM}}$ Microplate Absorbance Reader (Bio- 
Rad, Hercules, CA, USA). The cell viability percentage was calculated by comparing the absorbance values of compound-treated and vehicle-treated groups.

\subsection{Time-of-addition assays}

SK-N-SH cells seeded in 96-well plates were treated with $5 \mu \mathrm{M}$ EICAR, $5 \mu \mathrm{M}$ EICNR, or $50 \mu \mathrm{M}$ ribavirin for $1 \mathrm{~h}$ at $37^{\circ} \mathrm{C}$. After removal of culture medium, the treated cells were inoculated with CVS-Nluc (N-P) at an MOI of 0.1 for $1 \mathrm{~h}$. At 16 hpi, the cells were harvested and assayed for luciferase.

CVS-Nluc (N-P) was incubated with EICAR or EICNR at a final concentration of 20 $\mu \mathrm{M}$, or with ribavirin at a final concentration of $50 \mu \mathrm{M}$ for $1 \mathrm{~h}$ at $37^{\circ} \mathrm{C}$. Treated viruses were then used to infect confluent SK-N-SH cells seeded in 96-well plates at an MOI of 0.1. The infected cells were maintained in the absence of compounds and subsequently assayed for luciferase at 16 hpi.

SK-N-SH cells seeded in 96-well plates were infected with CVS-Nluc (N-P) at an MOI of 0.1 . After $1 \mathrm{~h}$ incubation at $37^{\circ} \mathrm{C}$, the viral inoculum was removed and replaced by fresh culture medium. At different time points post-infection $(0,2,4,6$, and $8 \mathrm{~h})$, the culture medium was replaced with media containing $5 \mu \mathrm{M}$ EICAR, $5 \mu \mathrm{M}$ EICNR, or $50 \mu \mathrm{M}$ ribavirin. The cells were then harvested at 16 hpi and assayed for luciferase.

\subsection{Plasmid construction and RABV minigenome assay}

Plasmids expressing Nluc-encoding minigenome of RABV-CVS (pCAGGS-RVDInluc) were generated following the construction strategy of firefly luciferase expressing pCAGGS-RVDI-luc (Okada et al., 2016). As a result, RABV-CVS minigenome contains 5' trailer region of RABV-CVS strain, an ORF of Nluc gene, the 3' leader region of RABVCVS strain instead. Three helper plasmids encoding RABV proteins N, P (phosphoprotein), 
or L (polymerase) were also constructed. A PCR-amplified fragment of N, P, or L genes containing an HA tag at the C-terminal end of each protein was inserted into pCXSN vectors. The resulting plasmids were designated pCXSN-N-HA(C), -P-HA(C), and -L-HA(C).

For the minigenome assay, NA cells seeded into 96-well plates were treated with serially diluted EICAR, EICNR, or ribavirin for $1 \mathrm{~h}$, and then transfected with the RABV plasmids as follows: 20 ng pCAGGS-RVDI-Nluc, 120 ng pCXSN-N-HA(C), 12 ng pCXSNP-HA(C), and 40 ng pCXSN-L-HA(C) using TransIT-Neural ${ }^{\circledR}$ (Mirus Bio LLC, Madison, WI, USA). At $72 \mathrm{~h}$ post-transfection, the cells were harvested and assayed for luciferase.

\subsection{Statistical analysis}

Statistical analyses used ANOVA with Dunnett’s post hoc test.

\section{Results}

\subsection{Antiviral activity and cytotoxicity of nucleoside analogs}

The antiviral activity of EICAR, EICNR, BICAR, mizoribine, and ribavirin (Fig. 1) was examined using rRABV in SK-N-SH cells. The anti-RABV activity of ribavirin was previously demonstrated by the rRABV expression of Nluc (Anindita et al., 2016). Thus, in the current study, ribavirin was used as a reference compound for RABV replication inhibition. The antiviral activity of each compound was indicated by a decrease in luciferase activity in serial dilutions of the compounds (Fig. 2A-E). EICAR, EICNR, BICAR, and ribavirin decreased the luciferase activity in a dose-dependent manner, while mizoribine did not exhibit anti-RABV activity. The EICAR-treated cells (Fig. 2A) showed the most significant inhibition of luciferase activity. The calculated $\mathrm{EC}_{50}$ values for EICAR, EICNR, BICAR, and ribavirin were $0.90,3.80,8.77$, and $18.55 \mu \mathrm{M}$, respectively. No SK-N-SH cytotoxicity was observed (Fig. 2). 
Since EICAR and EICNR demonstrated greater anti-RABV activity compared to ribavirin, their cytotoxic and antiviral activities were also examined in other RABV-susceptible cell lines, including NA, BHK-21 [C-13], and HEK 293T. No cytotoxic effects were observed in SK-N-SH, NA, and HEK 293T cells at the highest concentrations tested (200 $\mu \mathrm{M})$. A mild cytotoxicity was observed in BHK-21 [C-13] cells $\left(\mathrm{CC}_{50}, 158.26 \mu \mathrm{M}\right)$ by EICNR treatment (Table 1). The anti-RABV activity of EICAR and EICNR was revealed in NA, BHK-21 [C13] and HEK 293T cells with $\mathrm{EC}_{50}$ values ranging from $<0.16-0.90 \mu \mathrm{M}$, suggesting that their anti-RABV activity was not limited to SK-N-SH cells. EICAR and EICNR exhibited superior anti-RABV activity (20-27-fold and 5-10-fold, respectively) compared to that of ribavirin in all cell lines used in this study.

\subsection{Confirmation of EICAR and EICNR antiviral activity}

Immunofluorescence assays allowed direct visualization of the inhibition by EICAR, EICNR, and ribavirin on native RABV infection. All compounds demonstrated unambiguous inhibition (Fig. 3, left panels). Treatment of CVS-WT-infected SK-N-SH cells with each serially diluted compound revealed that they reduced the viral titers in the culture supernatants compared to DMSO-treated RABV-infected cells at 16 hpi. EICAR was the most effective anti-RABV compound (Fig. 3B-D; right panels).

\subsection{Time-of-addition effect of EICAR and EICNR on RABV life cycle}

To further determine the stage of the RABV life cycle that is inhibited by EICAR and EICNR treatment, we conducted time-of-addition assays. Treatment of SK-N-SH cells with EICAR, EICNR, or ribavirin prior to rRABV infection did not reveal any significant difference in luciferase activity ( $p \geq 0.05$ ), although a decrease of luciferase activity was observed in EICAR and ribavirin-treated cells (Fig. 4A). The possibility of direct virucidal 
activity of EICAR, EICNR, and ribavirin was assessed by treating rRABV with each compound prior to virus inoculation into SK-N-SH cells. No significant decrease of luciferase activity compared to the DMSO-treated control was observed (Fig. 4B, $p \geq 0.05$ ).

Inhibition of RABV replication after cell binding and entry was investigated by inoculation of SK-N-SH cells rRABV followed by treatment with EICAR, EICNR or ribavirin at different time points after inoculation (from 0-8 hpi). The cells were harvested for luciferase assay at $16 \mathrm{hpi}$. EICAR treatment at 0-6 hpi significantly decreased luciferase activity (Fig. 4C; 0-4 hpi, $p<0.001 ; 6$ hpi, $p<0.01$ ). In contrast, EICNR only demonstrated significant inhibition of RABV replication when treated at 0 hpi (Fig. 4D; $p<0.01$ ). Ribavirin demonstrated a significant inhibition when added to the cells at $0-2$ hpi (Fig. 4E; 0 hpi, $p<0.001 ; 2$ hpi, $p<0.01)$. Altogether, these data suggested that neither EICAR nor EICNR inhibited the viral attachment or entry stages and that they do not possess direct virucidal properties against RABV.

\subsection{Inhibition of viral transcription and genome replication by EICAR and EICNR}

Based on the performed experiments, the anti-RABV activity of EICAR and EICNR appeared to affect the virus after the attachment and entry stages. An RABV minigenome system was employed to determine whether EICAR and EICNR inhibited RABV transcription. The RABV-CVS minigenome plasmid expressing Nluc was co-transfected into NA cells together with helper plasmids encoding RABV N, P, and L, essential for RABV replication complex formation. Decreased Nluc expression demonstrated that all compounds exhibited a dose-dependent anti-RABV activity on viral transcription (Fig. 5). Interestingly, EICAR showed significant inhibitory effects at all tested concentrations $(0.2-5 \mu \mathrm{M}, p<$ 0.001; Fig. 5A). EICNR inhibited viral transcription at concentrations between 1.3-5 $\mu \mathrm{M}(1.3$ $\mu \mathrm{M}, p<0.01$; 2.5-5 $\mu \mathrm{M}, p<0.001$; Fig. 5B), while the inhibitory effects of ribavirin were 
6.3-50 $\mu \mathrm{M}(6.3 \mu \mathrm{M}, p<0.01 ; 12.5-50 \mu \mathrm{M}, p<0.001$; Fig. 5C). These results indicated that EICAR, EICNR, and ribavirin exert their anti-RABV activity through the inhibition of RABV at the transcription and replication stages. Both EICAR and EICNR were more potent than ribavirin. The anti-RABV activity of EICNR was more restricted to higher concentrations than those of EICAR in both the wild type and recombinant virus.

\subsection{Reversal of anti-RABV activity of EICAR, EICNR, and ribavirin in the presence of exogenous guanosine}

Since EICAR and EICNR are structurally related to ribavirin, we supposed that these two compounds acted similarly to ribavirin which exert its antiviral activity by depletion of the GTP pool via IMPDH inhibition (Debing et al., 2014; Leyssen et al., 2005). Therefore, we examined whether the addition of exogenous guanosine or other nucleosides (adenosine, cytidine, and uridine) would reverse the anti-RABV activity of EICAR, EICNR, and ribavirin. Firstly, we examined the potential anti-RABV activity of each nucleoside. RABV replication in SK-N-SH cells was not inhibited, even at the highest nucleoside concentration used in the experiment $(100 \mu \mathrm{M})$, and no cytotoxicity was observed (Table 2). A nucleoside addition assay was then conducted by treatment of RABV-infected SK-N-SH cells with EICAR, EICNR, or ribavirin in the presence of exogenous guanosine, adenosine, cytidine, or uridine. As shown in Table 3, the addition of $30 \mu \mathrm{M}$ guanosine was sufficient to reverse the antiRABV activity of EICAR $\left(\mathrm{EC}_{50}:>10 \mu \mathrm{M}\right)$, EICNR $\left(\mathrm{EC}_{50}:>10 \mu \mathrm{M}\right)$, and ribavirin $\left(\mathrm{EC}_{50}\right.$ : $>100 \mu \mathrm{M})$. The presence of other nucleosides did not affect the anti-RABV activity of any compound (Table 3).

\section{Discussion}


The lack of an approved effective drug to inhibit RABV infection after symptom onset poses a major global threat to human health. Therefore, there is an urgent need to identify new anti-RABV agents that can reduce rabies fatalities. Despite no apparent clinical efficacy observed in the administration of ribavirin (Appolinario and Jackson, 2015; Hemachudha et al., 2006; Warrell et al., 1989), the use of such a nucleoside analog should be considered when attempting to identify novel antiviral agents that inhibit RABV infection. Modifications of the chemical structure of this drug class could conceivably elicit superior anti-RABV effects.

In the present study, the anti-RABV activity of four ribavirin-related nucleoside analogs (EICAR, EICNR, BICAR, and mizoribine) was initially examined in SK-N-SH cells. EICAR and EICNR demonstrated greater anti-RABV activity than ribavirin. Other studies have reported that EICAR displayed a stronger broad-spectrum antiviral activity compared to ribavirin against a number of RNA viruses, including vesicular stomatitis virus, a prototype rhabdovirus belonging to the same viral family as RABV (De Clercq et al., 1991; Leyssen et al., 2005; Shigeta et al., 1992). Previous reports showed that EICAR had been determined a potent inhibitor of cell proliferation by inhibiting cellular DNA and RNA synthesis, but not protein synthesis, a phenomenon shared with ribavirin (De Clercq et al., 1991) and therefore the anti-RABV activity of EICAR, as well as EICNR which is structurally similar to EICAR, might be due to its direct effect on cellular metabolism. However, the cytotoxicity data from all tested cell lines indicates that the anti-RABV activities of EICAR and EICNR might not be related to this particular mechanism of action. On the other hand, mizoribine, a licensed immunosuppressive drug in Europe and Japan, failed to demonstrate anti-RABV activity although this compound has been reported to inhibit ortho- and paramyxoviruses to a lesser extent than EICAR and ribavirin in vitro (Kosugi et al., 1994). 
Along with ribavirin, EICAR and EICNR are potential compound models that inhibit RABV infection. Initial investigation of the antiviral targets of EICAR and EICNR revealed that they did not likely act at the viral entry step or directly inactivate the virus (Fig. 4A, B). These compounds inhibited rRABV Nluc reporter gene expression when they were added to RABV-infected cells in the early stages of viral infection: post attachment and entry into the target cells (Fig. 4C-E). Importantly, EICAR could decrease the expression of Nluc when the RABV-infected cells were treated until 6 hpi, thus suggesting the potency of EICAR usage after the infection has been established. These results imply that EICAR and EICNR might interfere directly with viral transcription in a similar manner as observed previously with EICAR and ribavirin in other RNA viruses (De Clercq et al., 1991; Leyssen et al., 2005; Shigeta et al., 1992).

It is plausible that EICAR and EICNR inhibit RABV transcription in a similar manner to ribavirin (Appolinário et al., 2013; Bussereau and Ermine, 1983; Crotty et al., 2000) because both compounds are ribavirin analogs. Using an RABV minigenome assay system, we demonstrated that EICAR and EICNR were capable of blocking viral transcription because the Nluc expression decreased in a dose-dependent manner (Fig. 5). As ribavirin administration also decreased Nluc expression, this observation relates to a previous observation where ribavirin was found to dose-dependently inhibit RABV RNA and protein synthesis (Bussereau and Ermine, 1983).

Previous studies have demonstrated that EICAR acts as an IMPDH inhibitor by a similar mechanism of action to that proposed for ribavirin (Leyssen et al., 2005; Shigeta et al., 1992). Inside the cell, EICAR is metabolized to EICAR 5'-monophosphate, sharing a similar binding site on IMPDH as IMP (Balzarini et al., 1993). IMPDH inhibition reduces the level of guanine nucleotide pool. Evidence in support of this proposed mechanism has been provided by reversing the antiviral activity of EICAR and ribavirin with the addition of 
exogenous guanosine (Balzarini et al., 1993; Dal Pozzo et al., 2010; Debing et al., 2014; Jashés et al., 2000; Leyssen et al., 2005). In our study, we demonstrated the reversal of the anti-RABV activity of EICAR, EICNR, and ribavirin in the presence of guanosine, suggesting that these compounds exerted their anti-RABV activity through GTP pool depletion, possibly by IMPDH inhibition. It would be useful to directly quantify the level of intracellular GTP during the treatment of RABV-infected cells with these compounds to directly clarify this point.

The marked difference between EICAR and ribavirin is a substitution of the $\mathrm{N}$ at position 2 of the triazole ring with an alkynyl-carbon moiety, while EICNR is the 4-cyano derivative of EICAR (Fig. 1). This structural difference might contribute to the enhancement of the anti-RABV activity of EICAR and EICNR compared to ribavirin. Further structureactivity relationship studies need to be performed to elucidate the detailed mechanism of antiRABV activity of these compounds.

Altogether, these findings suggest that EICAR and EICNR are more potent anti-RABV compounds than ribavirin by inhibiting viral replication and transcription, which in turn reemphasizes the potency of nucleoside analogs as a class of compounds feasible for the development of human rabies treatment. Further investigations are required to determine the inhibitory effect of EICAR and EICNR on RABV replication in vivo using mice models of RABV infection.

\section{Acknowledgments}

This study was supported in part by a Grant-in-Aid for Scientific Research on Innovative Areas from the Ministry of Education, Culture, Sports, Science and Technology of Japan (grant numbers 16H06429, 16H06431, 16K21723), the Japan Society for the Promotion of Science KAKENHI (15K07716), and the Japan Agency for Medical Research 
and Development/Japan International Cooperation Agency within the framework of the Science and Technology Research Partnership for Sustainable Development. 


\section{References}

Anindita, P.D., Sasaki, M., Nobori, H., Sato, A., Carr, M., Ito, N., Sugiyama, M., Orba, Y., Sawa, H., 2016. Generation of recombinant rabies viruses encoding NanoLuc luciferase for antiviral activity assays. Virus Res 215, 121-128.

Appolinario, C.M., Jackson, A.C., 2015. Antiviral therapy for human rabies. Antivir Ther 20, $1-10$.

Appolinário, C.M., Prehaud, C., Allendorf, D., de Paula Antunes, J.M.A., Peres, M.G., Lafon, M., Megid, J., 2013. Ribavirin has an in vitro antiviral effect in rabies virus infected neuronal cells but fails to provide benefit in experimental rabies in mice. Journal of Virology and Antiviral Research 2.

Balzarini, J., Karlsson, A., Wang, L., Bohman, C., Horská, K., Votruba, I., Fridland, A., Van Aerschot, A., Herdewijn, P., De Clercq, E., 1993. Eicar (5-ethynyl-1-beta-Dribofuranosylimidazole-4-carboxamide). A novel potent inhibitor of inosinate dehydrogenase activity and guanylate biosynthesis. J Biol Chem 268, 24591-24598.

Banyard, A.C., Mansfield, K.L., Wu, G., Selden, D., Thorne, L., Birch, C., Koraka, P., Osterhaus, A.D.M.E., Fooks, A.R., 2017. Re-evaluating the effect of Favipiravir treatment on rabies virus infection. Vaccine.

Baranovich, T., Wong, S.S., Armstrong, J., Marjuki, H., Webby, R.J., Webster, R.G., Govorkova, E.A., 2013. T-705 (favipiravir) induces lethal mutagenesis in influenza A H1N1 viruses in vitro. J Virol 87, 3741-3751.

Benarroch, D., Egloff, M.P., Mulard, L., Guerreiro, C., Romette, J.L., Canard, B., 2004. A structural basis for the inhibition of the NS5 dengue virus mRNA 2'-O-methyltransferase domain by ribavirin 5'-triphosphate. J Biol Chem 279, 35638-35643. 
Bussereau, F., Chermann, J.C., Clercq, E.D., Hannoun, C., 1983. Search for compounds which have an inhibitory effect on rhabdovirus multiplication in vitro. Annales de l'Institut Pasteur/Virologie 134, 124-134.

Bussereau, F., Ermine, A., 1983. Effects of heteropolyanions and nucleoside analogues on rabies virus: in vitro study of syntheses and viral production. Annales de l'Institut Pasteur/Virologie 134, 487-506.

Bussereau, F., Picard, M., Blancou, J., Sureau, P., 1988. Treatment of rabies in mice and foxes with antiviral compounds. Acta Virol 32, 33-49.

Chávez, J.H., Leal, P.C., Yunes, R.A., Nunes, R.J., Barardi, C.R., Pinto, A.R., Simões, C.M., Zanetti, C.R., 2006. Evaluation of antiviral activity of phenolic compounds and derivatives against rabies virus. Vet Microbiol 116, 53-59.

Crotty, S., Maag, D., Arnold, J.J., Zhong, W., Lau, J.Y., Hong, Z., Andino, R., Cameron, C.E., 2000. The broad-spectrum antiviral ribonucleoside ribavirin is an RNA virus mutagen. Nat Med 6, 1375-1379.

Dal Pozzo, F., Galligioni, V., Vaccari, F., Gallina, L., Battilani, M., Scagliarini, A., 2010. Antiviral efficacy of EICAR against canine distemper virus (CDV) in vitro. Res Vet Sci 88, 339-344.

De Clercq, E., Cools, M., Balzarini, J., Snoeck, R., Andrei, G., Hosoya, M., Shigeta, S., Ueda, T., Minakawa, N., Matsuda, A., 1991. Antiviral activities of 5-ethynyl-1-beta-Dribofuranosylimidazole-4- carboxamide and related compounds. Antimicrob Agents Chemother 35, 679-684.

Debing, Y., Emerson, S.U., Wang, Y., Pan, Q., Balzarini, J., Dallmeier, K., Neyts, J., 2014. Ribavirin inhibits in vitro hepatitis E virus replication through depletion of cellular GTP pools and is moderately synergistic with alpha interferon. Antimicrob Agents Chemother 58, 267-273. 
Hemachudha, T., Sunsaneewitayakul, B., Desudchit, T., Suankratay, C., Sittipunt, C., Wacharapluesadee, S., Khawplod, P., Wilde, H., Jackson, A.C., 2006. Failure of therapeutic coma and ketamine for therapy of human rabies. J Neurovirol 12, 407-409.

Jackson, A.C., 2013. Current and future approaches to the therapy of human rabies. Antiviral Res 99, 61-67.

Jashés, M., Mlynarz, G., De Clercq, E., Sandino, A.M., 2000. Inhibitory effects of EICAR on infectious pancreatic necrosis virus replication. Antiviral Res 45, 9-17.

Jordheim, L.P., Durantel, D., Zoulim, F., Dumontet, C., 2013. Advances in the development of nucleoside and nucleotide analogues for cancer and viral diseases. Nat Rev Drug Discov $12,447-464$.

Kosugi, Y., Saito, Y., Mori, S., Watanabe, J., Baba, M., Shigeta, S., 1994. Antiviral Activities of Mizoribine and other Inosine Monophosphate Dehydrogenase Inhibitors against Several Ortho- and Paramyxoviruses. Antiviral Chemistry and Chemotherapy 5, 366-371.

Leyssen, P., Balzarini, J., De Clercq, E., Neyts, J., 2005. The predominant mechanism by which ribavirin exerts its antiviral activity in vitro against flaviviruses and paramyxoviruses is mediated by inhibition of IMP dehydrogenase. J Virol 79, 1943-1947.

Lingappa, U.F., Wu, X., Macieik, A., Yu, S.F., Atuegbu, A., Corpuz, M., Francis, J., Nichols, C., Calayag, A., Shi, H., Ellison, J.A., Harrell, E.K., Asundi, V., Lingappa, J.R., Prasad, M.D., Lipkin, W.I., Dey, D., Hurt, C.R., Lingappa, V.R., Hansen, W.J., Rupprecht, C.E., 2013. Host-rabies virus protein-protein interactions as druggable antiviral targets. Proc Natl Acad Sci U S A 110, E861-868.

Minakawa, N., Takeda, T., Sasaki, T., Matsuda, A., Ueda, T., 1991. Nucleosides and nucleotides. 96. Synthesis and antitumor activity of 5-ethynyl-1-beta-Dribofuranosylimidazole-4-carboxamide (EICAR) and its derivatives. J Med Chem 34, 778786. 
Okada, K., Ito, N., Yamaoka, S., Masatani, T., Ebihara, H., Goto, H., Nakagawa, K., Mitake, H., Okadera, K., Sugiyama, M., 2016. Roles of the Rabies Virus Phosphoprotein Isoforms in Pathogenesis. J Virol 90, 8226-8237.

Rupprecht, C.E., Gibbons, R.V., 2004. Prophylaxis against Rabies. New England Journal of Medicine 351, 2626-2635.

Shah, N.R., Sunderland, A., Grdzelishvili, V.Z., 2010. Cell type mediated resistance of vesicular stomatitis virus and Sendai virus to ribavirin. PLoS One 5, e11265.

Shigeta, S., Mori, S., Baba, M., Ito, M., Honzumi, K., Nakamura, K., Oshitani, H., Numazaki, Y., Matsuda, A., Obara, T., 1992. Antiviral activities of ribavirin, 5-ethynyl-1-beta-Dribofuranosylimidazole-4-carboxamide, and 6'-(R)-6'-C-methylneplanocin A against several ortho- and paramyxoviruses. Antimicrob Agents Chemother 36, 435-439.

Sun, Y., Chung, D.H., Chu, Y.K., Jonsson, C.B., Parker, W.B., 2007. Activity of ribavirin against Hantaan virus correlates with production of ribavirin-5'-triphosphate, not with inhibition of IMP dehydrogenase. Antimicrob Agents Chemother 51, 84-88.

Wada, Y., Orba, Y., Sasaki, M., Kobayashi, S., Carr, M.J., Nobori, H., Sato, A., Hall, W.W., Sawa, H., 2017. Discovery of a novel antiviral agent targeting the nonstructural protein 4 (nsP4) of chikungunya virus. Virology 505, 102-112.

Warrell, M.J., White, N.J., Looareesuwan, S., Phillips, R.E., Suntharasamai, P., Chanthavanich, P., Riganti, M., Fisher-Hoch, S.P., Nicholson, K.G., Manatsathit, S., 1989. Failure of interferon alfa and tribavirin in rabies encephalitis. BMJ 299, 830-833.

Yamada, K., Noguchi, K., Komeno, T., Furuta, Y., Nishizono, A., 2016. Efficacy of Favipiravir (T-705) in Rabies Postexposure Prophylaxis. J Infect Dis 213, 1253-1261. 


\section{Figure legends}

Figure 1. Structure of the compounds used in this study.

(A) EICAR, (B) EICNR, (C) BICAR, (D) Mizoribine, and (E) Ribavirin.

\section{Figure 2. Cytotoxicity and antiviral activity of compounds.}

SK-N-SH cells seeded in 96-well plates were treated with EICAR (A), EICNR (B), BICAR (C), mizoribine (D), or ribavirin (E) for $1 \mathrm{~h}$ before infection with CVS-Nluc (N-P) at an MOI of 0.1 . The infected cells were cultured in the presence of each compound for 24 hpi and then harvested for luciferase assay. The compounds' anti-RABV effects were presented as relative inhibition rate calculated by normalizing the Nluc activities derived from compound-treated and infected cells with those derived from DMSO-treated and infected cells. Columns and solid circles represent the relative inhibition rate and the cell viability, respectively. Data shown represents the mean and standard deviation from two independent experiments performed in triplicate.

Figure 3. Confirmation of inhibitory effect of EICAR, EICNR, and ribavirin using immunofluorescence assay and virus titration.

SK-N-SH cells were infected with CVS-WT at an MOI of 5 for $1 \mathrm{~h}$ and treated with DMSO (A) or serially diluted $10 \mu \mathrm{M}$ EICAR (B), $10 \mu \mathrm{M}$ EICNR (C), or $100 \mu \mathrm{M}$ ribavirin (D) for 16 h. The culture supernatants were harvested, and virus titers were determined by focus forming assays. The cells were fixed with $10 \%$ formaldehyde before staining with FITCconjugated monoclonal antibody directed to RABV N and Hoechst 33342 to stain cell nuclei. The images shown are representatives of the RABV-infected cells treated with the highest concentration of each compound. Scale bar represents $100 \mu \mathrm{m}$. RABV titer data are representative of two independent experiments performed in triplicate. Mean and standard 
deviation is shown. Statistical analyses used one-way ANOVA with Dunnett's post hoc test $\left({ }^{* *} p<0.01,{ }^{* * *} p<0.001\right)$.

\section{Figure 4. Time-of-addition of EICAR, EICNR, and ribavirin to RABV-infected cells.}

(A) SK-N-SH cells were treated with DMSO, EICAR $(10 \mu \mathrm{M})$, EICNR $(10 \mu \mathrm{M})$, or ribavirin $(50 \mu \mathrm{M})$ for $1 \mathrm{~h}$ before infection with CVS-Nluc (N-P) at an MOI of 0.1. Infected cells were incubated in fresh culture medium without supplementation of any compounds and subjected to luciferase assay at 16 hpi. (B) CVS-Nluc (N-P) was incubated with DMSO, EICAR (20 $\mu \mathrm{M})$, EICNR (20 $\mu \mathrm{M})$, or ribavirin $(50 \mu \mathrm{M})$ for $1 \mathrm{~h}$ prior to infection of SK-N-SH cells at an MOI of 0.1 . At 16 hpi, the cells were harvested and subjected to luciferase assay following culture with fresh culture medium containing no compounds. (C-E) SK-N-SH cells were inoculated with CVS-Nluc (N-P) at MOI of 0.1 for $1 \mathrm{~h}$. At $0-8 \mathrm{hpi}$, a final concentration of 5 $\mu \mathrm{M}$ EICAR (C), $5 \mu \mathrm{M}$ EICNR (D), or $50 \mu \mathrm{M}$ ribavirin (E) was added to the cells. VC, virus control (infected-cells treated with DMSO). All presented data are representative of three independent experiments performed in triplicate. Mean and standard deviation are shown. Statistical analyses used one-way ANOVA with Dunnett's post hoc test $\left({ }^{* *} p<0.01\right.$, ${ }^{* * *} p<$ $0.001)$.

Figure 5. Effects of EICAR, EICNR, and ribavirin treatment on minigenome-based gene expression.

SK-N-SH cells were transfected with a minigenome plasmid expressing Nluc together with helper plasmids expressing the RABV replication complex: $N, P$, and $L$ in the presence of serially diluted EICAR (A), EICNR (B), or ribavirin (C). All presented data are representative of three independent experiments performed in triplicate. Mean and standard 
deviation are shown. Statistical analyses were done using one-way ANOVA with Dunnett‘s post hoc test $\left({ }^{* *} p<0.01,{ }^{* * *} p<0.001\right)$. 


\section{Table 1}

Cytotoxicity and antiviral activity of EICAR, EICNR, and ribavirin

\begin{tabular}{|c|c|c|c|c|c|c|}
\hline \multirow{2}{*}{ Cell line } & \multicolumn{3}{|c|}{ Cytotoxicity $\left[\mathrm{CC}_{50}(\mu \mathrm{M})\right]^{\mathrm{a}}$} & \multicolumn{3}{|c|}{ Antiviral activity $\left[\mathrm{EC}_{50}(\mu \mathrm{M})\right]^{\mathrm{b}}$} \\
\hline & EICAR & EICNR & Ribavirin & EICAR & EICNR & Ribavirin \\
\hline SK-N-SH & $>200$ & $>200$ & $>200$ & 0.90 & 3.80 & 18.55 \\
\hline NA & $>200$ & $>200$ & $>200$ & $<0.16$ & 0.63 & 4.22 \\
\hline BHK-21 & $>200$ & 158.26 & $>200$ & 0.17 & 0.48 & 4.61 \\
\hline HEK293T & $>200$ & $>200$ & $>200$ & 0.45 & 1.07 & 6.62 \\
\hline
\end{tabular}

a The cytotoxic concentration $\left(\mathrm{CC}_{50}\right)$ is defined as the concentration required to reduce cell viability of a given cell line by $50 \%$. The data represent mean values from three independent experiments.

$\mathrm{b}$ The effective concentration $\left(\mathrm{EC}_{50}\right)$ is defined as the concentration required to reduce NanoLuc activity of a given rRABV-infected-cell line by $50 \%$. The data represent mean values from three independent experiments. 
Table 2

Cytotoxicity and antiviral activity of each nucleoside against RABV*

\begin{tabular}{lcc}
\hline Nucleoside & Cytotoxicity $\left[\mathbf{C C}_{\mathbf{5 0}}(\boldsymbol{\mu M})\right]$ & Antiviral activity $\left[\mathbf{E C}_{\mathbf{5 0}}(\boldsymbol{\mu M})\right]$ \\
\hline Guanosine & $>100$ & $>100$ \\
Adenosine & $>100$ & $>100$ \\
Cytidine & $>100$ & $>100$ \\
Uridine & $>100$ & $>100$ \\
\hline
\end{tabular}

${ }^{*}$ The $\mathrm{EC}_{50}$ values are based on the measurement of Nluc signal. The data represent mean values from three independent experiments. 


\section{Table 3}

Antiviral activity of EICAR, EICNR, and ribavirin following the addition of nucleoside ${ }^{\ddagger}$

\begin{tabular}{lccc}
\hline \multirow{2}{*}{ Nucleoside $(\mathbf{3 0} \boldsymbol{\mu M})$} & \multicolumn{3}{c}{ Antiviral activity $\left[\mathbf{E C}_{\mathbf{5 0}}(\boldsymbol{\mu M})\right]$} \\
\cline { 2 - 4 } & EICAR & EICNR & Ribavirin \\
\hline No nucleoside & 0.89 & 3.43 & 27.92 \\
Guanosine & $>10$ & $>10$ & $>100$ \\
Adenosine & 1.08 & 4.09 & 29.15 \\
Cytidine & 1.03 & 3.81 & 27.41 \\
Uridine & 0.86 & 4.15 & 28.83 \\
\hline
\end{tabular}

${ }^{\ddagger}$ The $\mathrm{EC}_{50}$ values are based on the measurement of Nluc signal. The data represent mean values from three independent experiments. 
Figure 1

A

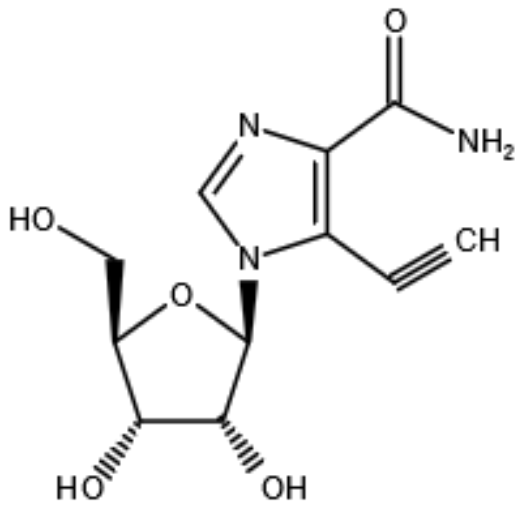

C

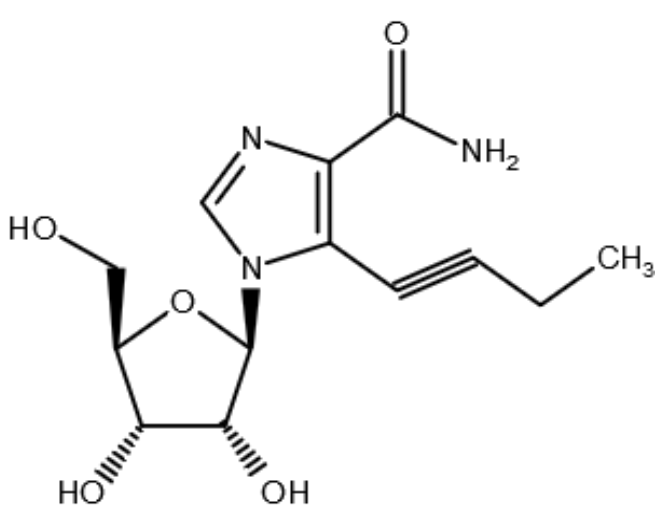

E

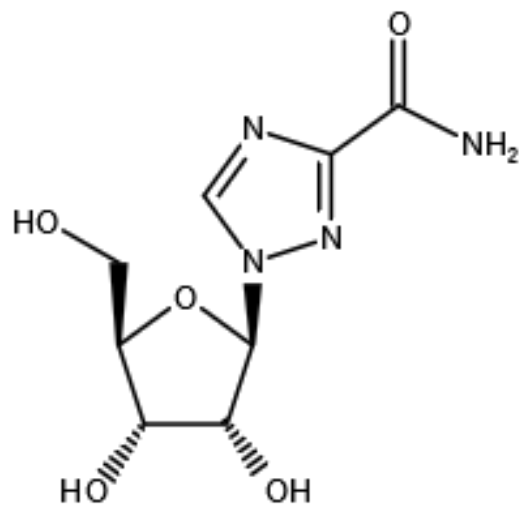

B

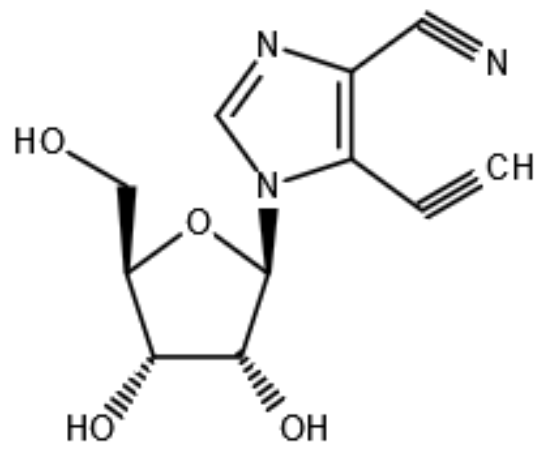

D

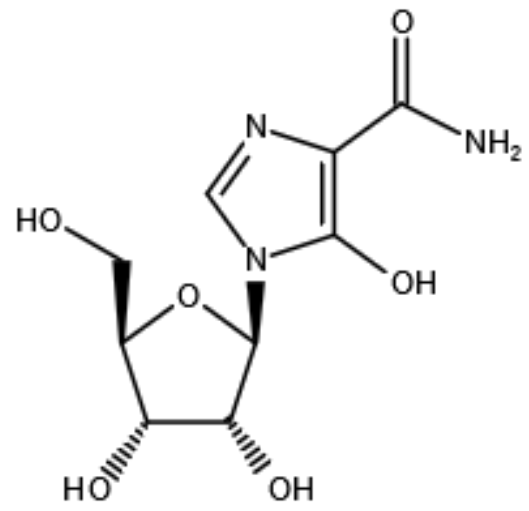


Figure 2

A

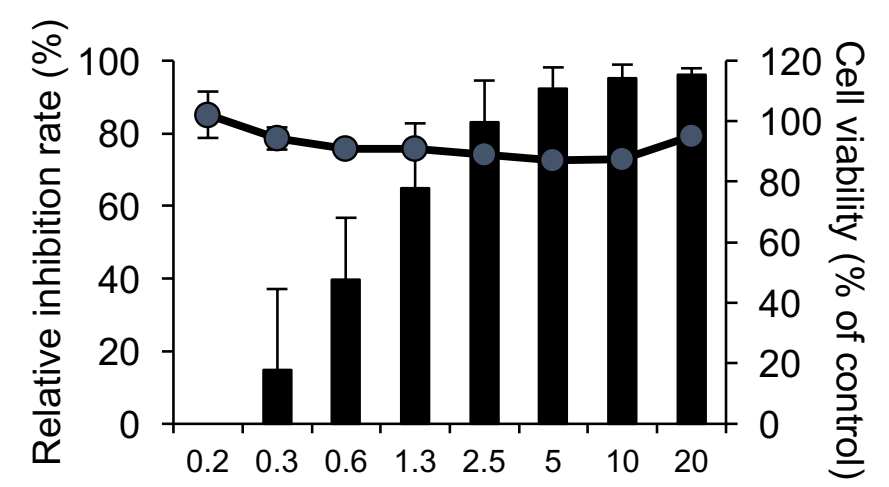
$\operatorname{EICAR}(\mu \mathrm{M})$

C

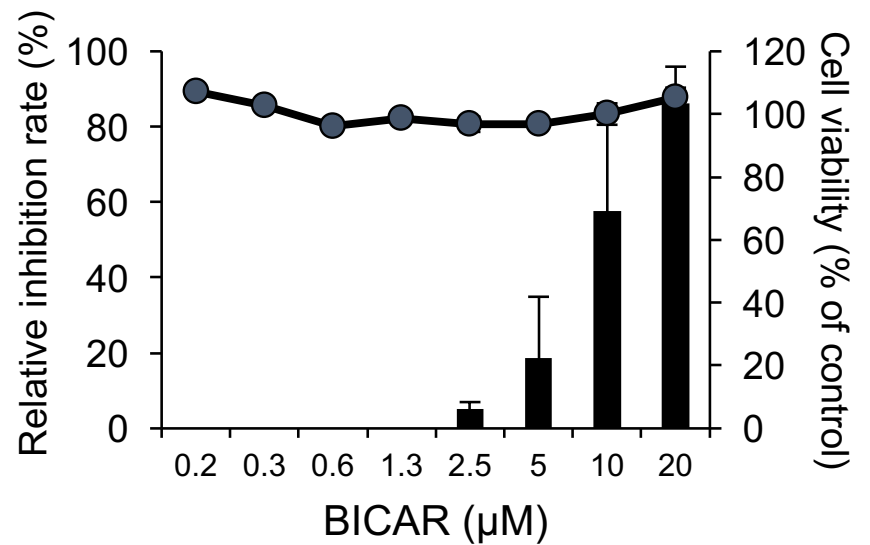

E

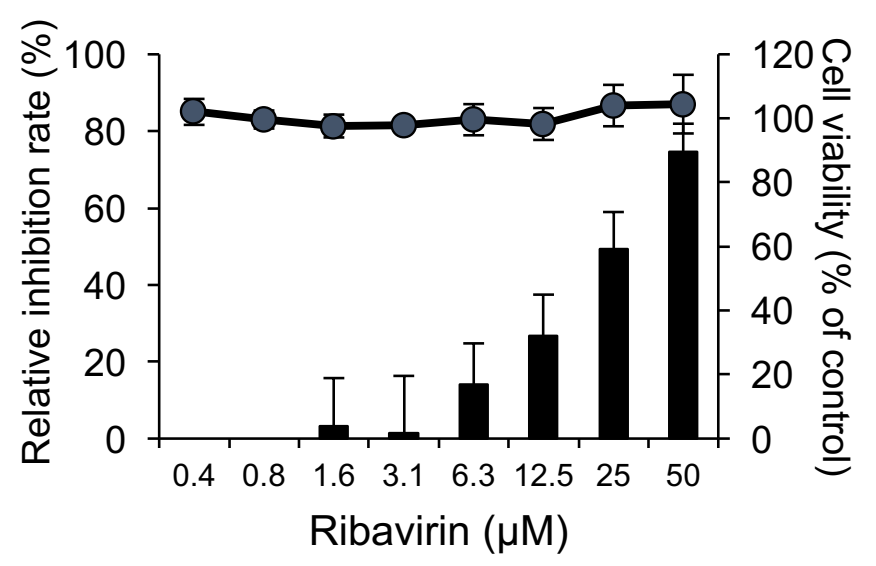

B

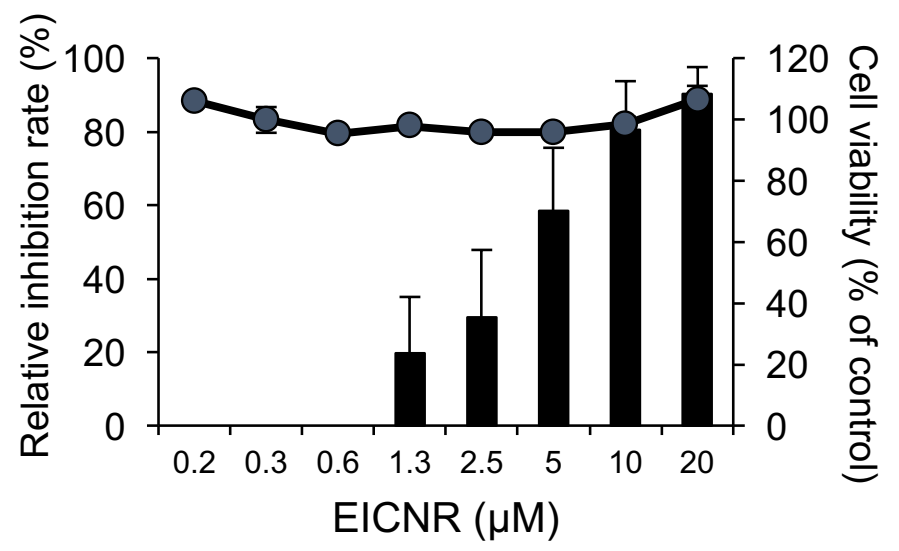

D

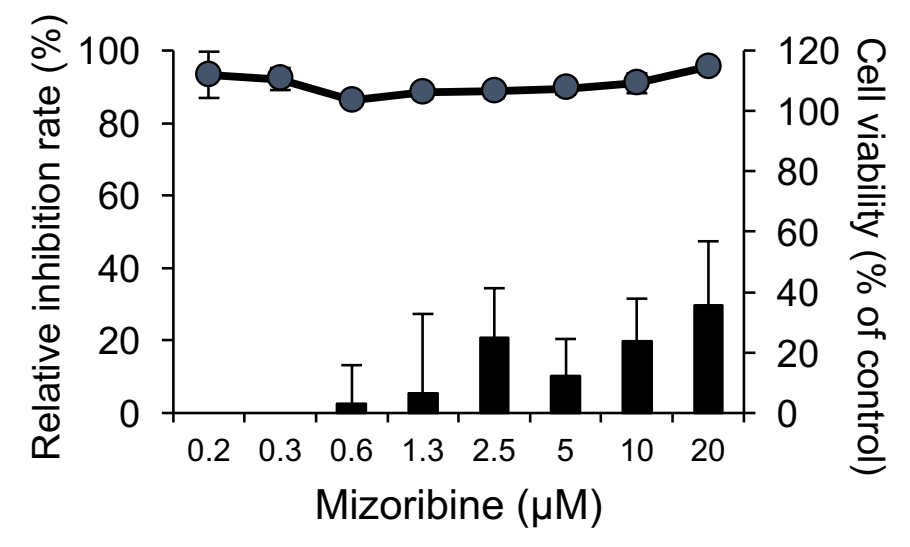




\section{Figure 3}

A No compound

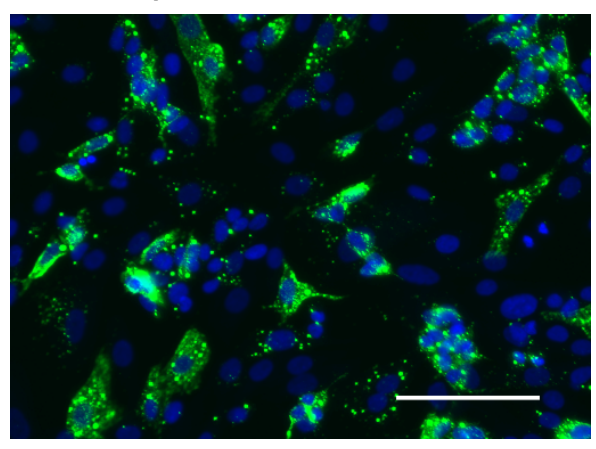

B $\operatorname{EICAR}(10 \mu \mathrm{M})$
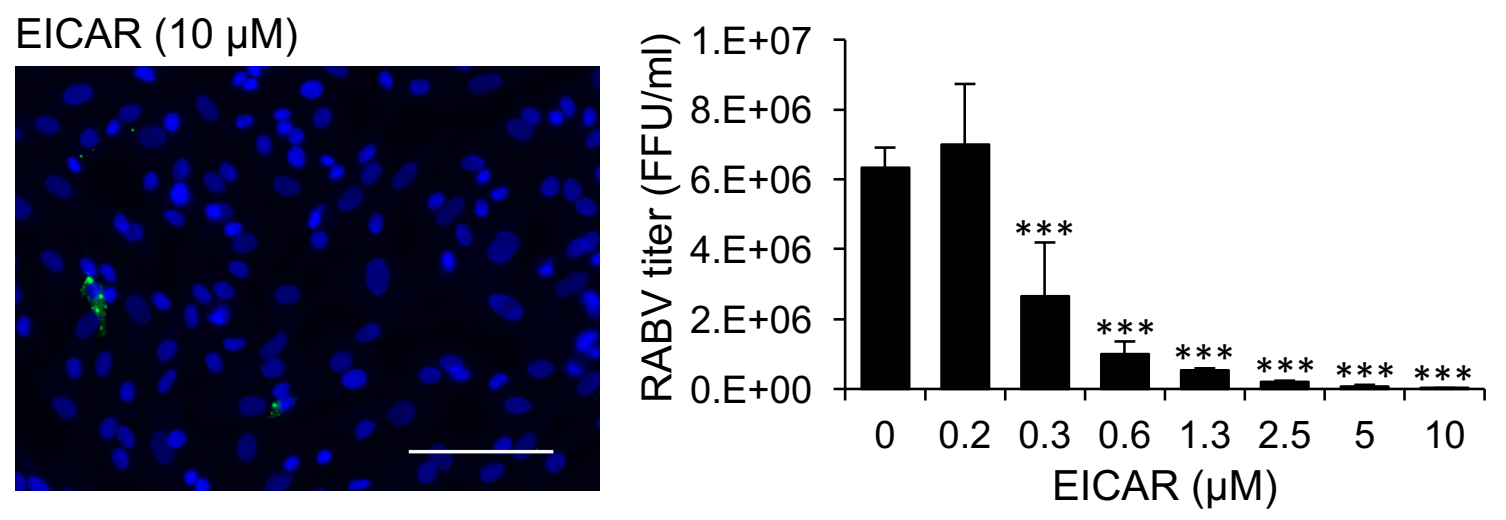

C $\operatorname{EICNR}(10 \mu \mathrm{M})$
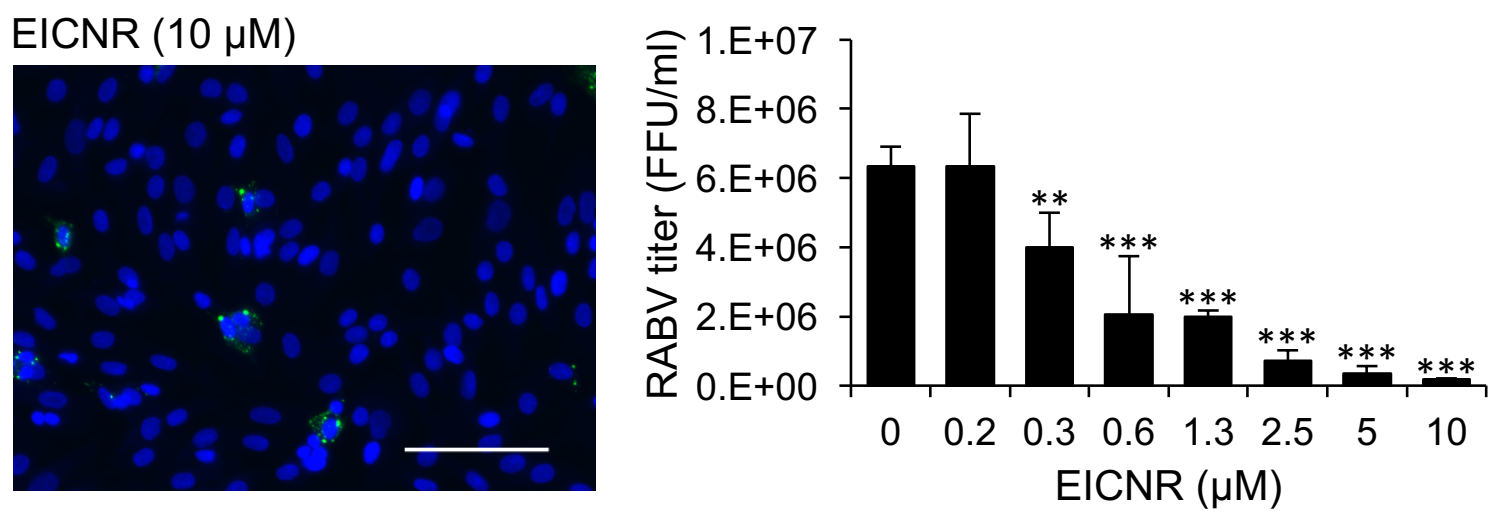

D Ribavirin $(100 \mu \mathrm{M})$
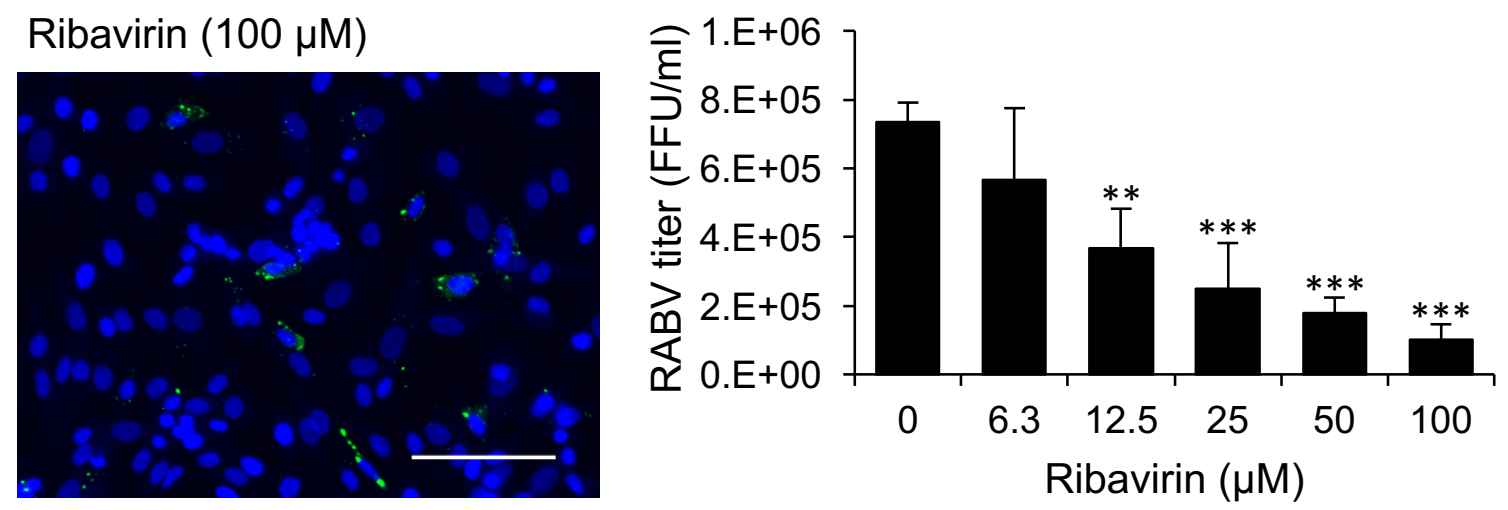
Figure 4

A

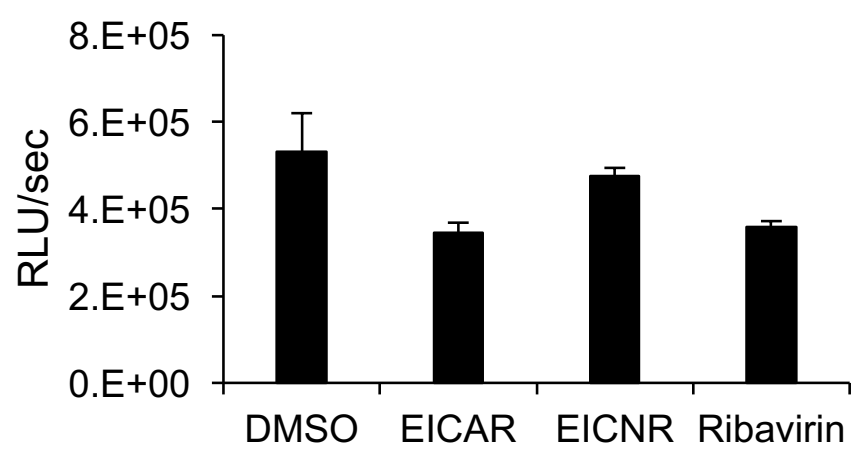

B

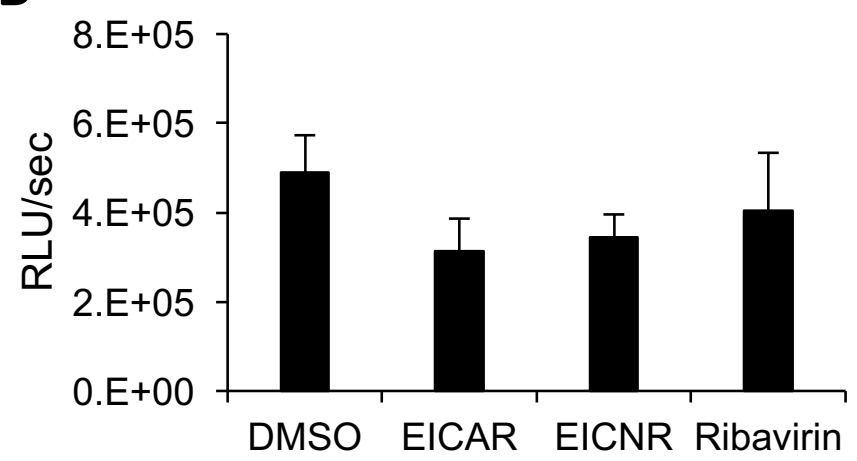

C

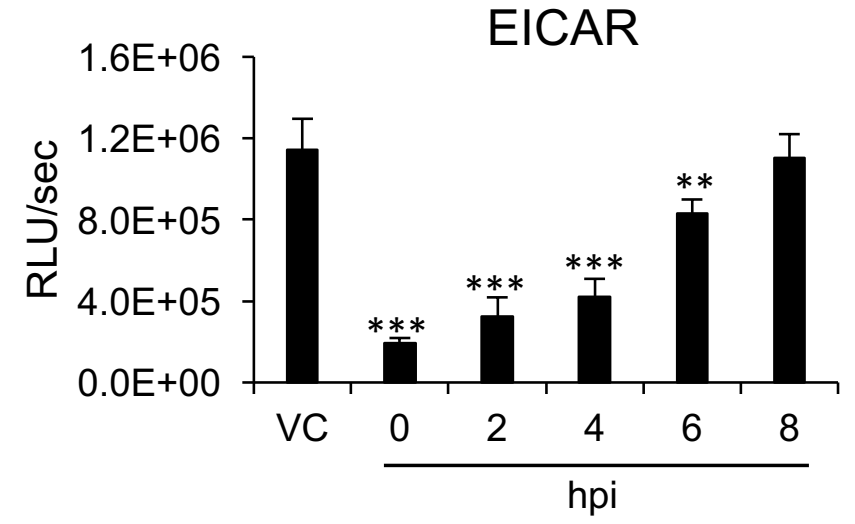

E

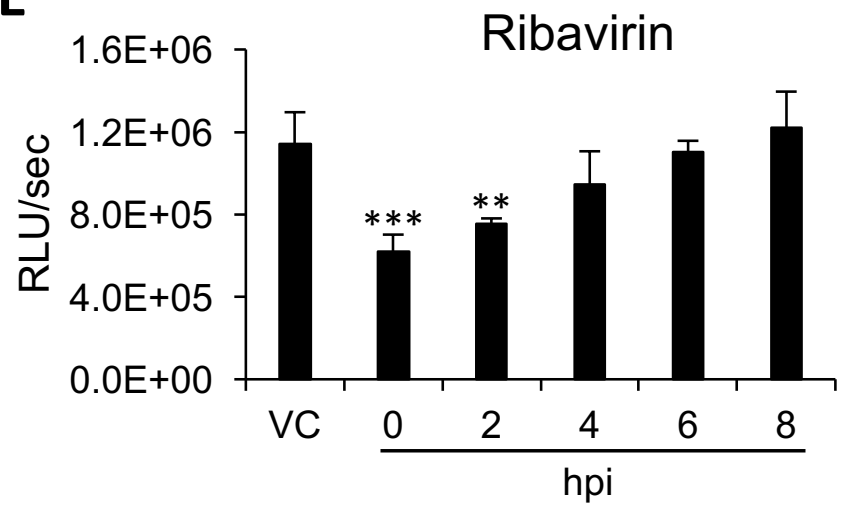

D

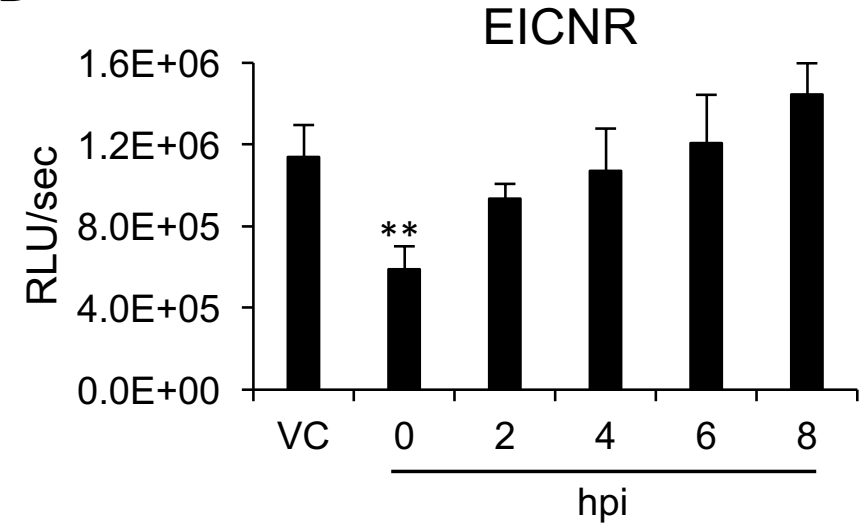


Figure 5
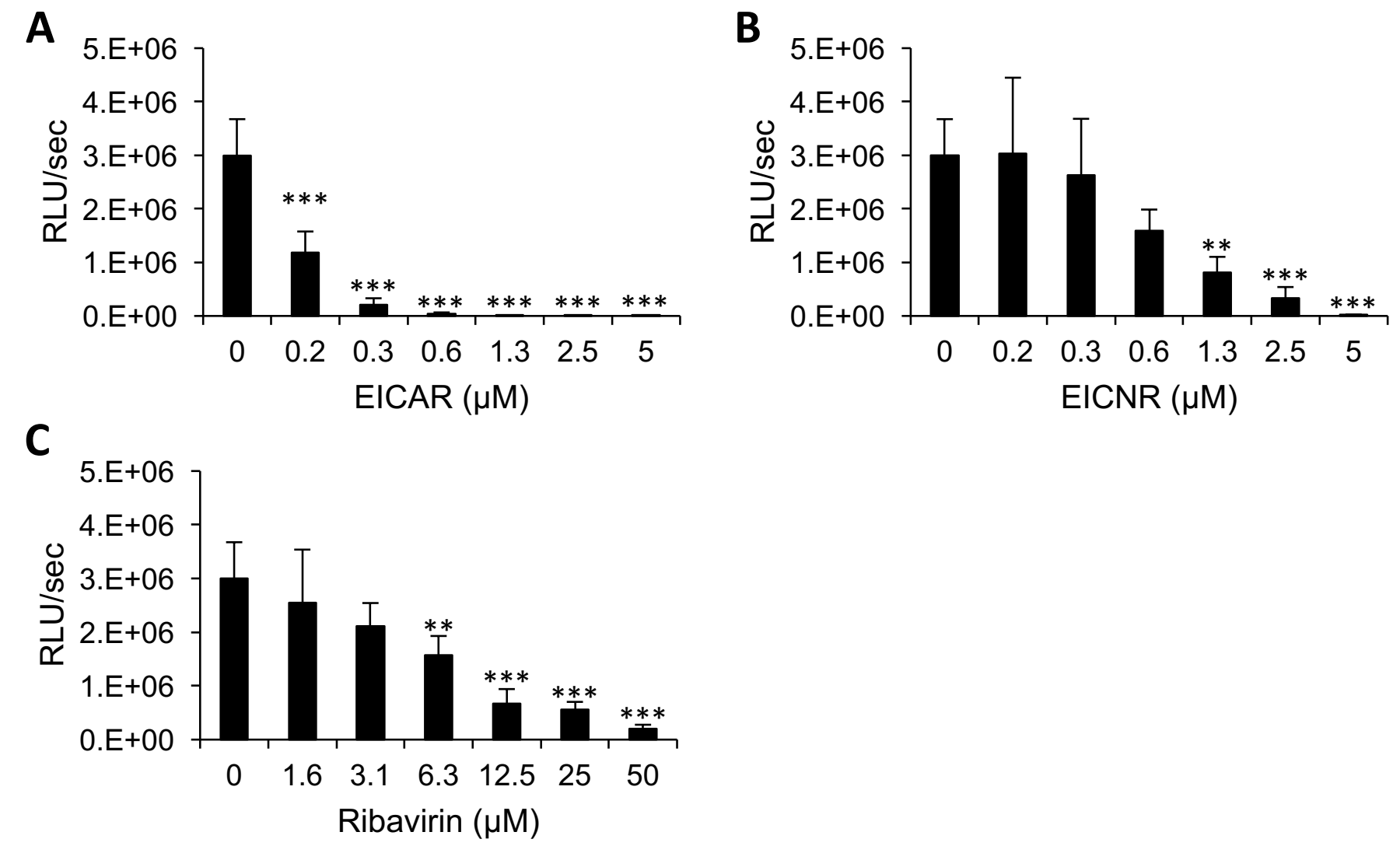
Table 1

Cytotoxicity and antiviral activity of EICAR, EICNR, and ribavirin

\begin{tabular}{|c|c|c|c|c|c|c|}
\hline \multirow{2}{*}{ Cell line } & \multicolumn{3}{|c|}{ Cytotoxicity $\left[\mathrm{CC}_{50}(\mu \mathrm{M})\right]$} & \multicolumn{3}{|c|}{ Antiviral activity $\left[\mathrm{EC}_{\mathbf{5 0}}(\boldsymbol{\mu M})\right]$} \\
\hline & EICAR & EICNR & Ribavirin & EICAR & EICNR & Ribavirin \\
\hline SK-N-SH & $>200$ & $>200$ & $>200$ & 0.90 & 3.80 & 18.55 \\
\hline NA & $>200$ & $>200$ & $>200$ & $<0.16$ & 0.63 & 4.22 \\
\hline BHK-21 & $>200$ & 158.26 & $>200$ & 0.17 & 0.48 & 4.61 \\
\hline HEK293T & $>200$ & $>200$ & $>200$ & 0.45 & 1.07 & 6.62 \\
\hline
\end{tabular}

a The cytotoxic concentration $\left(\mathrm{CC}_{50}\right)$ is defined as the concentration required to reduce cell viability of a given cell line by $50 \%$. The data represent mean values from three independent experiments.

$\mathrm{b}$ The effective concentration $\left(\mathrm{EC}_{50}\right)$ is defined as the concentration required to reduce NanoLuc activity of a given $\mathrm{rRABV}$-infected-cell line by $50 \%$. The data represent mean values from three independent experiments. 
Table 2

Cytotoxicity and antiviral activity of each nucleoside against RABV*

\begin{tabular}{lcc}
\hline Nucleoside & Cytotoxicity $\left[\mathbf{C C}_{\mathbf{5 0}}(\boldsymbol{\mu M})\right]$ & Antiviral activity $\left[\mathrm{EC}_{\mathbf{5 0}}(\boldsymbol{\mu M})\right]$ \\
\hline Guanosine & $>100$ & $>100$ \\
Adenosine & $>100$ & $>100$ \\
Cytidine & $>100$ & $>100$ \\
Uridine & $>100$ & $>100$ \\
\hline
\end{tabular}

${ }^{*}$ The $\mathrm{EC}_{50}$ values are based on the measurement of Nluc signal. The data represent mean values from three independent experiments.

Table 3

Antiviral activity of EICAR, EICNR, and ribavirin following the addition of nucleoside

\begin{tabular}{lccc}
\hline \multirow{2}{*}{ Nucleoside $(\boldsymbol{\mu M})$} & \multicolumn{3}{c}{ Antiviral activity $\left[\mathbf{E C}_{\mathbf{5 0}}(\boldsymbol{\mu M})\right]$} \\
\cline { 2 - 4 } & EICAR & EICNR & Ribavirin \\
\hline No nucleoside & 0.89 & 3.43 & 27.92 \\
Guanosine 30 & $>10$ & $>10$ & $>100$ \\
Adenosine 30 & 1.08 & 4.09 & 29.15 \\
Cytidine 30 & 1.03 & 3.81 & 27.41 \\
Uridine 30 & 0.86 & 4.15 & 28.83 \\
\hline
\end{tabular}

${ }^{\ddagger}$ The $\mathrm{EC}_{50}$ values are based on the measurement of Nluc signal. The data represent mean values from three independent experiments. 